\title{
Could suicide be a marker of economic distress?
}

\author{
Abstract \\ Are suicides causally related to an economic crisis or recession? This commentary \\ sheds light on this fundamental question.
}

Volume 5 Issue I - 2018

\author{
John E Berg \\ Oslo Metropolitan University, Norway \\ Correspondence: John E Berg, Professor, Oslo Metropolitan \\ University/Oslo Met, Faculty of Health Sciences, Pilestredet 48, \\ 0130 Oslo, Norway, Tel +47-67235000, +47-92090438, \\ Email john@pong.no
}

Received: January 25, 2017| Published: February 19, 2018

\section{Introduction}

Suicides occur in all populations, both sexes and at all ages, the result of a process, the details of which we do scarcely know. On the other hand, intuitively sudden or large changes of circumstances in life may influence personal or population health. A priori the direction of the influence is not obvious, although popular thinking presupposes a detrimental effect if the circumstance is an economic crisis. $^{1}$ The last economic crisis of 2007-8 has spurred interest in understanding purported health effects of an economic crisis. A group under the auspices of Ralph Catalano warns that although undesirable job and financial experiences increase the risk of psychological and behavioural disorders, many other suspected associations as cardiovascular disease, depression and suicide remain poorly studied or unsupported. ${ }^{2}$ While WHO firmly discourages the practice of straight data comparisons between countries, nobody actually seems to care. ${ }^{1}$ Level of economic crisis and rates of suicide may interact during a crisis, but empirical studies vary widely. One reason might be the insufficient clarity in defining them. This study argues that a hypothesis of increased suicide rates during an economic crisis is untoward.

Life expectancy improved during major economic recessions, like the Great Depression in the US from 1929 to 1932 and in the crisis in Europe in 2007-2009 according to a study from 2012. ${ }^{3}$ The authors also showed that in 2009 life expectancy increased most rapidly in European countries where the decrease in gross domestic product was greatest, i.e. in Estonia, Latvia and Lithuania. These results could give important information in planning and administering changes relevant for extending life expectancy without essential costs. In a study by Laanani et al. ${ }^{4}$ unemployment and suicide rates were found to be statistically associated but very weakly. ${ }^{4} \mathrm{~A}$ "crisis effect" was inconsistent across countries and was interpreted as an argument against a causal effect. Impact of unemployment on suicide rates is shown to be offset by the presence of generous state social and unemployment benefit programs (as in Norway), though effects are small or inconclusive. ${ }^{5,6}$ Another study using historical life expectancy and mortality data to examine associations of economic growth with population health for the period 1920 to 1940 found that the population health did not decline during 1930-1933..$^{7}$ On the contrary population health generally improved during the 4 years of the Great Depression 1930-33, with mortality decreasing for almost all ages, and life expectancy increasing by several years in males, females, whites and non-whites. Mortality tended to peak during years of strong economic expansion in the period 1920 to 1940 . The only exception was suicide mortality that increased during the Great Depression. Although the rate increased, suicides comprised only $2 \%$ of all deaths. Suicides are often connected to the medical condition depression, but suicides do occur also among people without a trace of depression. Whereas women in rural India commit suicide out of poverty and harsh family relations using pesticides, old men in Norway, not exposed to an unemployment risk (suicide rate above 70 years 29.8/100000 in one study 8 ) and other European countries find their lives useless and have a rate higher than in the working age groups. When suicide is not accepted in society, even national statistics may be inaccurate. An eruption of publications started in the light of the Orthodox Church in Greece stating that suicide is a deplorable moral act, and an ensuing underestimation of suicide cases in the public statistics. This was very prominent when living conditions during the economic downturn of 2007 deteriorated. Several articles have highlighted the impact of the crisis on mental health, usually through suicide, although mental health problems are not the only reason for a suicide during a crisis. Persons with severe mental illness are only indirectly affected by an economic crisis as they do not participate in the work force. Lay-offs and reductions in wages may influence the ability of peers to support them, but barely increase their risk of committing suicide.

Several papers concentrate on the increasing suicide rates in Greece after $2008 .^{9-15}$ In a new study by the group around Kentikelenis and Stuckler the text gives an increase in suicide rates from 2007 to 2011 of $45 \%$, but the accompanying figure shows in men a decrease from 2006 to 2007 and the increase during the period read from the figure is from 280 to 380 from 2007 to 2011 , i.e. an increase of $35 \% .{ }^{16}$ The numbers are very low compared to for instance Norway with near double rates without a crisis and with less than half the population. Including all suicides among the health consequences of an economic downturn would therefore be inaccurate. Stuckler et al. ${ }^{17}$ used another dataset to study mortality during the Great Depression in urban populations. ${ }^{17}$ Cause specific mortality was linked to bank suspensions and income data. Incidentally the authors did not report the number of bank suspensions they based their analysis on. They found reductions in all-cause mortality for pneumonia, flu and respiratory tuberculosis, but an increase for heart disease, cancer and diabetes. They maintain that only heart disease can plausibly be related to the contemporaneous economic shocks. But even this factor may not be plausibly related to an economic crisis, as the notion of heart disease is a too complex one. Heart disease is the result of a long-time development of risk for sudden or gradual death. It may thus quite accidentally occur during an economic crisis. 
Figure 1 further illustrates the lack of direct connection between suicide rates and an economic recession for the period 1980 to 2012 . The left Y-axis depicts number of suicides per year for men and women separately in Hungary and Norway. The right Y-axis gives GDP at current PPPs (in million 2005US\$). In Hungary, the suicide rate was halved and continued to do so from 2007 and onward, whereas the increase in GDP was modest from a low level. Hardship in the population was accompanied with a substantial reduction in the suicide rate. In Norway, the suicide rate staid put during the same period or had a slight not statistically significant increase although the prosperity of the country increased substantially.
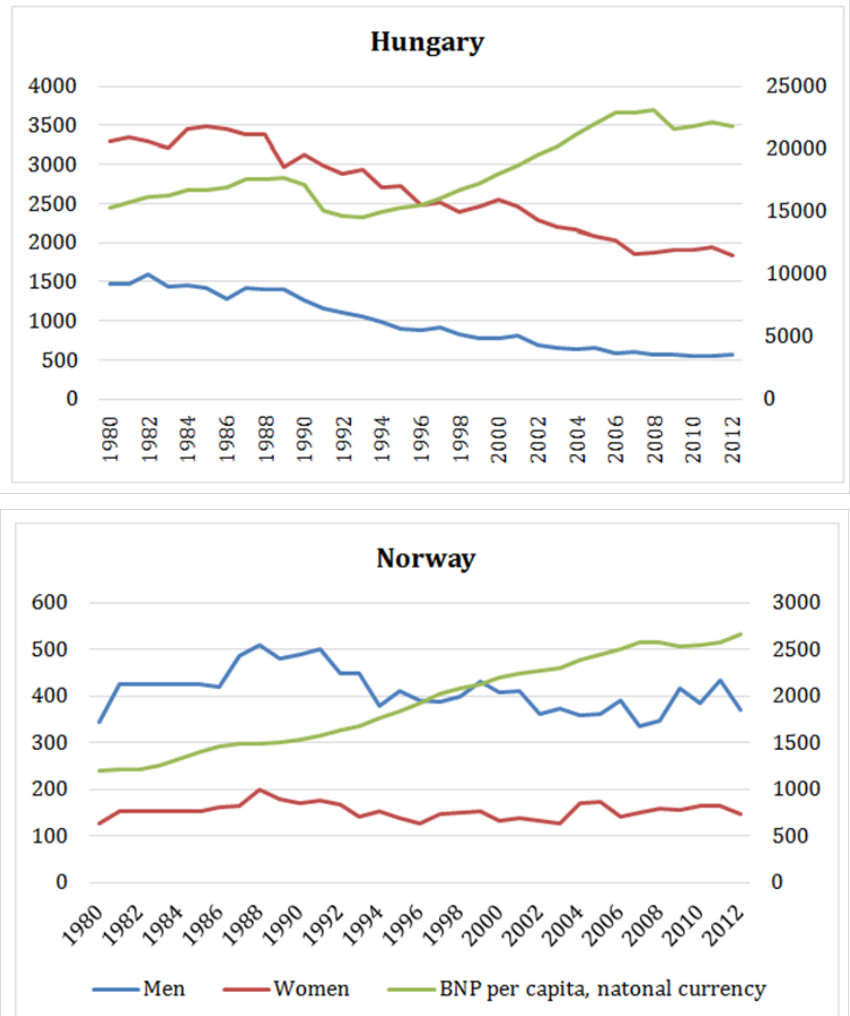

Figure I Number of deaths - Intentional self-harm, all ages, WHO (+Berg, $+\mathrm{SSB}$ ) and GDP per capita (Expenditure-side real GDP at current PPPs (in mil. 2005US\$)

\section{Conclusion}

Time lag between the start of a crisis and the documented health effect may be long; often many years, and thus show its effect long time after the crisis has subsided. An increase in suicides during a crisis would be the sum effect of health and life circumstances before and during the crisis. No studies have been found showing the separate effect of these two factors. The untoward use of specific diagnostic entities in studies of health effects of an economic crisis give the impression of causal relationship between the crisis and the purported health effects. What are often shown are correlations without proof of a psycho-biological explanation of findings. Different disease categories have distinct developmental paths. Correlations found must be further studied to ascertain a causal link between the disease and the economic crisis. A hypothesis of a causal link, at the current state of clinical knowledge and clarity of the crisis definition, is far from being ascertained by current research.

\section{Acknowledgements}

The assistance of PhD Anne Grethe Tøge (of the Faculty of Social Sciences of Oslo Met) in gathering and presenting data is highly appreciated.

\section{Conflict of interest}

The authors declare that there is no conflict of interests regarding the publication of this paper.

\section{References}

1. De Leo D. Can we rely on suicide mortality data? Crisis. 2015;36(1):1-3.

2. Catalano R, Goldman-Mellor S, Saxton K, et al. The health effects of economic decline. Annu Rev Public Health. 2011;32:431-450.

3. Kristjuhan U, Taidre E. The last recession was good for life expectancy. Rejuvenation Res. 2012;15(2):134-135.

4. Laanani M, Ghosn W, Jougla E, et al. Impact of unemployment variations on suicide mortality in Western European countries (200-2010). $J$ Epidemiol Community Health. 2014;69(2):103-109.

5. Cylus J, Glymour M, Avendano M. Do generous unemployment benefit programs reduce suicide rates? A state fixed-effect analysis covering 1968 - 2008. Am J Epidemiol. 2014;180(1):45-52.

6. Baumbach A, Gulis G. Impact of financial crisis on selected health outcomes in Europe. Eur J Public Health. 2014;24(3):399-403.

7. Granados JAT, Roux AVD. Life and death during the Great Depression. PNAS. 2009;106(41):17290-17295.

8. Kjølseth I, Ekeberg Ø, Teige B. Suicide among the elderly in Norway. Tidsskr Nor Legeforen. 2002;122(15):1457-1461.

9. Costa G, Marra M, Salmaso S, et al. Health indicators in the time of crisis in Italy. Epidemiol Prev. 2012;36(6):337-366.

10. Stuckler D, Basu S, Suhrcke M, et al. The public health effect of economic crises and alternative policy responses in Europe: an empirical analysis. Lancet. 2009;374(9686):315-323.

11. Fountoulakis KN, Savopoulos C, Siamouli M, et al. Trends in suicidality amid the economic crisis in Greece. Eur Arch Psychiatry Clin Neurosci. 2013;263(5):441-444.

12. De Vogli R, Marmot M, Stuckler D. Strong evidence that the economic crisis caused a rise in suicides in Europe: the need for social protection. $J$ Epidemiol Community Health. 2013;67(4):298.

13. Kondilis E, Giannakopoulos S, Gavana M, et al. economic crisis, restrictive policies, and the population's health and health care: the Greek case. Am J Public Health. 2013;103(6):973-979.

14. Kentikelenis A, Karanikolos M, Papanicolas I, et al. Health effects of financial crisis: omens of a Greek tragedy. Lancet. 2011;378(9801):1457-1458.

15. McDaid D, Quaglio G, Correia de Campos A, et al. Health protection in times of economic crisis: challenges and opportunities for Europe. $J$ Public Health Policy. 2013;34(4):489-501.

16. Kentikelenis A, Karanikolos M, Reeves A, et al. Greece's health crisis from austerity to denialism. Lancet. 2014;383(9918):748-753.

17. Stuckler D, Meissner C, Fishback P, et al. Banking crisis and mortality during the Great Depression: evidence from US urban populations, 19291937. J Epidemiol Community Health. 2012;66(5):410-419. 